\title{
9p21.3 locus is associated to poor glycemic control on risk of coronary artery disease in a type 2 Diabetic Tunisian population
}

\author{
Abid Kaouthar*, Mili Donia and Kenani Abderraouf \\ Laboratory of biochemistry, UR 12ES08, Faculty of Medicine, Monastir University, Tunisia
}

\begin{abstract}
Background: Several single nucleotide polymorphisms (SNPs) on chromosome $9 \mathrm{p} 21.3$ were associated with increased risk of coronary artery disease (CAD) in the general population. Nevertheless, the extent of this effect in the population with type 2 diabetes (T2D) has not been yet well described. The objective of the current study was to investigate the association of 3 variants of the 9p21.3 locus with CAD in type 2 diabetic Tunisian patients and evaluate its interaction with poor glycemic control.

Methods: The case-control study population consisted of 634 consecutive type 2 diabetic patients undergoing a routine coronary angiography to evaluate suspected $\mathrm{CAD}$. The association between SNP rs2383206 and CAD was defined as angiographically documented stenosis greater than $50 \%$ in a major coronary artery or a main branch thereof. Cohort study: cumulative 5-year mortality.

Results: Homozygous patients for the risk allele were significantly more frequent in case than control subjects ( 41.3 vs. $27.9 \%$, $p=0.0002)$. This association was unaffected by adjustment for cardiovascular risk factors, but the effect of the risk genotype was significantly magnified (adjusted $\mathrm{p}$ for interaction $=0.046$ ) in the presence of poor glycemic control (worst tertile of the distribution of HbA1c at examination). Relative to the CAD risk for patients with neither a $9 \mathrm{p} 21.3$ risk allele nor poor glycemic control, the $\mathrm{CAD}$ risk for subjects having two risk alleles but not poor glycemic control was increased two-fold $(\mathrm{OR}=1.98,0.98-3.11)$, while the risk for study subjects with the same genotype and with poor glycemic control was increased four-fold $(\mathrm{OR}=4.25,2.24-8.02)$. The same interaction between $9 \mathrm{p} 21.3$ variant and poor glycemic control was observed with regards to cumulative 5 -year mortality in the cohort study ( $43.7 \%$ in patients with two risk alleles and poor glycemic control, $23.2 \%$ in those with only the two risk alleles, $30.1 \%$ in those with only poor glycemic control, and $31.5 \%$ in those with neither factor, $p$ for interaction=0.035).

Conclusions: The poor glycemic control increased the CAD risk associated with the 9p21.3 variant in type 2 diabetic Tunisian population.
\end{abstract}

Abbreviations: CAD: Coronary Artery Disease, ETT: Exercise Treadmill Test, HbA1c: Glycated Haemoglobin, HDL: High Density Lipoprotein, LDL: Low Density Lipoprotein, OR: Odds Ratio, SNPs: Single Nucleotide Polymorphisms, T2D: Type 2 Diabetes

\section{Introduction}

Diabetes mellitus remains the most important coronary artery disease risk factor. The lifetime risk of a major cardiac event to people with diabetes is increased by a factor of 2 to 4 relative to people without diabetes [1]. It compounds the impact of such events with increased risks of re-infarction, congestive heart failure, and death [2]. Diabetes is also a major determinant of peripheral artery disease and stroke $[3,4]$. These profound effects are the results of an acceleration of atherosclerosis caused by hyperglycemia and other characteristics of the diabetic milieu, such as hyperlipidemia (particularly small LDL cholesterol particles) and hypertension [5].

Several family studies demonstrate that a substantial proportion of cardiovascular risk is under the control of genetic factors [6,7]. Although this proof has been collected principally in the general population, studies of indicators of preclinical atherosclerosis propose that genetic factors also play an important role in the progress of atherosclerosis in the presence of diabetes $[8,9]$. So if the hypothesis that: the genes that play a role in the absence of diabetes are likely to play a role also in its presence is true, it invites the question if the increased cardiovascular disease risk seen in diabetes is mediated by interaction of those same genes with the diabetic milieu.

In two of our recent studies concerning 9p21.3 variant's association with CAD in a Tunisian population, we found that $9 \mathrm{p} 21.3$ was not associated with the development, but with the severity and the early onset of CAD in type 2 diabetic patients [10,11]. Recent genome wide association studies found association of a common allele on chromosome 9p21 with coronary artery disease in the general population $[12,13]$. In the current study, we investigated the association of this allele with CAD in type 2 diabetic Tunisian patients and if the association is modified by the severity of hyperglycemia, the defining characteristic of diabetes.

Correspondence to: Abid Kaouthar, Laboratory of biochemistry, UR 12ES08, Faculty of Medicine, Monastir University, Monastir, Tunisia, Tel: 0021673462 200, Fax: 0021673460 737, E-mail: kaouthar_abid@yahoo.fr

Key words: coronary artery disease, poor glycemic control, single nucleotide polymorphisms, type 2 diabetes, 9p21.3 locus

Received: August 10, 2016; Accepted: August 23, 2016; Published: August 26, 2016 


\section{Methods}

\section{Patients}

For the case-control study, a total of 434 type 2 diabetic patients, recruited through the Fattouma Bourguiba hospital (Monastir, Tunisia), were diagnosed by angiography. The study protocol and informed consent procedures were approved by the Fattouma Bourguiba hospital ethical committee chaired by Pr ABROUG Fekri. All subjects gave written informed consent. Type 2 diabetes was defined as diabetes that was diagnosed after age 30 according to ADA criteria [14] and did not require insulin treatment for at least two years after its diagnosis. Study subjects comprised 222 cases with diagnosed CAD and 212 controls that did not have clinical evidence of CAD. CAD-positive case patients were a random sample of patients with type 2 diabetes who had a stenosis greater than $50 \%$ in a major coronary artery or a main branch thereof that was documented by cardiac catheterization at the Cardiology Department of CHU Fattouma Bourguiba between 2011 and 2012. All cases were enrolled in the study at the time of catheterization and examined within one month from the procedure. CAD-negative controls were randomly selected from among patients who were identified between 2011 and 2016 as satisfying the following criteria: 1 . current age between 55 and 74 years; 2 . type 2 diabetes for five years or more; 3 . negative cardiovascular history (i.e., normal resting EKG, absence of cardiac symptoms, and no hospitalization for cardiovascular events); and 4. normal response to an exercise treadmill test (ETT, [15]) performed for screening purposes. All controls were recruited within 6 months from the ETT. A questionnaire was fulfilled at the time of examination for each patient in which detailed informations concerning: history of myocardial infarction, smoking, hypertension, hypercholesterolemia and treatment with glucoselowering drugs were determined. Data on medications were confirmed by review of medical records.

For the prospective study, a group of 325 Tunisian patients was recruited, in 2010 for genetic studies of type 2 diabetes and its complications, to evaluate the interaction between $9 \mathrm{p} 21.3$ variant and poor glycemic control with respect to all-cause and cardiovascular mortality. The study protocol and informed consent procedures were approved by CHU Fattouma Bourguiba Committee on Human Studies. All subjects gave written informed consent. Study participants were a random sample of type 2 diabetic patients from the CHU Fattouma Bourguiba enriched with patients with proteinuria [16]. All subjects had diabetes diagnosed after age 25 and were treated with diet or oral agents for at least two years after the diagnosis. Their survival status was updated as of December 31, 2015.

\section{Severity of hyperglycemia}

For the case-control study, glycated haemoglobin (HbAlc) was measured by a high-performance liquid chromatography (Biorad, Richmond, CA) by the CHU Fattouma Bourguiba Hospital biochemistery Laboratory. The intra- and inter-assay coefficients of variation for this measurement were $0.25 \%$ and $2.1 \%$, respectively. For the prospective study, all $\mathrm{HbAlc}$ values measured in these subjects since 2010 were abstracted from the CHU Fattouma Bourguiba Hospital electronic medical records.

\section{SNP genotyping}

Genotyping was realized as previously described by Scheffold et al. [17].

Genotyping of the investigated SNPs (rs1333049, rs2383206, and rs 10757278) was carried out by real time PCR and subsequent melting curve analysis on a LightCycler 480 instrument (Roche Applied Science; Mannheim, Germany). The primers and hybridization probes were designed and synthesized by Tib MolBiol GmbH (Berlin, Germany). PCR was carried out in 96-well plates (Roche Applied Science; Mannheim, Germany) using $12.5 \mathrm{ng}$ of genomic DNA as template in a final reaction volume of $5 \mu$ l. Reaction mixtures contained $0.5 \mu \mathrm{M}$ of each primer, $0.15 \mu \mathrm{M}$ of SNP-specific hybridization probes and $1 \mu \mathrm{l}$ of LightCycler 480 Genotyping Master (Taq DNA polymerase, reaction buffer, $15 \mathrm{mM} \mathrm{MgCl}_{2}$, and a dNTP mixture with UTP instead of dTTP) (Roche Diagnostics GmbH, Mannheim, Germany). The cycling program consisted of 10 minutes of initial denaturation at $95^{\circ} \mathrm{C}$, followed by 35 cycles of denaturation at $95^{\circ} \mathrm{C}$ for 5 seconds, annealing at $53^{\circ} \mathrm{C}$ (rs1333049, $\left.\mathrm{rs} 2383206\right)$ or at $62^{\circ} \mathrm{C}$ ( $\left.\mathrm{rs} 10757278\right)$ for 10 seconds, and extension at $72^{\circ} \mathrm{C}$ for 10 seconds. After PCR melting curves were generated by holding the reaction mixture at $95^{\circ} \mathrm{C}$ for 1 minute, stepwise lowering of the temperature to $65^{\circ} \mathrm{C}, 55^{\circ} \mathrm{C}$ and $45^{\circ} \mathrm{C}$, holding for 30 seconds at each temperature, lowering to $40^{\circ} \mathrm{C}$ for 2 minutes, followed by continuously heating to $75^{\circ} \mathrm{C}$. Melting curve analyses were conducted using the LightCycler 480 software according to the manufacturer's instructions (Roche Diagnostics GmbH; Mannheim, Germany).

\section{Statistical analysis}

All statistical analyses were performed as described previously by Doria et al. [18].

For the case-control study, all statistical analyses were performed using version 11.0 of the Statistical Package for the Social Sciences: SPSS (SPSS Inc., Chicago, Illinois, USA). Genotype distributions were tested at both polymorphic loci for departure from Hardy-Weinberg equilibrium and compared between study groups by Fisher exact tests. Allele frequencies were derived from genotype counts and compared between groups also by Fisher exact tests. Odds ratios of CAD for SNP rs2383206 and other relevant predictors were estimated by logistic regression analysis using first a univariable model for each predictor and then a multivariable model including all variables showing a significant effect $(\mathrm{p}<0.05)$. For examining the interaction of genotype with hyperglycemia, rs2383206 was represented as an additive model (number of risk alleles), $\mathrm{HbA1c}$ as an indicator variable for the highest tertile, and the interaction as the product of the HBAlc variable by an indicator variable for patients homozygous for the risk allele. Power was estimated by means of the software QUANTO (http://hydra.usc. edu/gxe), assuming a risk allele frequency of 0.55 . For both SNPs, there was $80 \%$ power $(\alpha=0.05)$ to detect associations with CAD with ORs as low as 1.35 per risk allele and to detect a 2.5 -fold difference in the ORs for risk allele homozygotes between top and lower two tertiles of $\mathrm{HbA1c}$. The latter calculation assumed a CAD prevalence of 0.25 and marginal ORs of 1.80 for $\mathrm{G} / \mathrm{G}$ vs. $\mathrm{A} / \mathrm{G}+\mathrm{A} / \mathrm{A}$ and 1.45 for the top tertile vs. the lower two tertiles of $\mathrm{HbAlc}$.

For the prospective study, life-table methods were used to estimate the cumulative 5-year mortality and its standard error within each stratum defined by degree of glycemic control and rs2383206 genotype. The significance of the interaction between these two variables was determined by comparing the effect of glycemic control on cumulative mortality in $\mathrm{G} / \mathrm{G}$ homozygotes with that in carriers of other genotypes. This linear contrast, divided by its standard error, was compared to the standard normal distribution. The presence of interaction was also tested by adding a cross-product term to a Cox proportional hazard model including glycemic control and rs2383206 genotype together 
with age at baseline and gender as main effects. The assumption of proportionality of the hazards was tested by adding time interaction terms to the model.

\section{Results}

\section{Clinical characteristics of cases and controls}

Table 1 shows clinical characteristics of the study subjects with type 2 diabetes according to their CAD status. Case subjects had significant angiographically-confirmed CAD and control subjects had a negative cardiovascular history and normal exercise treadmill test. Age at examination, age at diagnosis of diabetes, and body weight were the same in the two groups. HbAlc (a measure of poor glycemic control) averaged a little higher in those with rather than without CAD. This difference was completely owing to an excess of CAD cases in the worst tertile of $\mathrm{HbAlc}$, consistent with a non-linear relationship between poor glycemic control and CAD risk. Percentage of insulin therapy was more frequent in cases with CAD than control subjects $(50.1 \%$ as compared with $39.1 \%$ ), as was a history of hypertension $(80.2 \%$ as compared to $70.2 \%)$. A history of smoking was almost twice as common in case subjects as in control subjects $(64.4 \%$ as compared

Table 1. Clinical characteristics of study subjects with type 2 diabetes according to coronary artery disease status.

\begin{tabular}{|c|c|c|}
\hline & \multicolumn{2}{|c|}{ Type 2 Diabetes } \\
\hline & CAD-Negative & CAD-Positive \\
\hline $\mathrm{N}$ & 212 & 222 \\
\hline Men (\%) & $115(54.6)$ & $157(71.1)$ \\
\hline Age at examination (yrs) & $63 \pm 5$ & $64 \pm 6$ \\
\hline Age at Diabetes Dx (yrs) & $51 \pm 7$ & $51 \pm 10$ \\
\hline Diabetes Duration (yrs) & $13 \pm 6$ & $14 \pm 9$ \\
\hline Previous MI (\%) & - & $100(44.9)$ \\
\hline Percent IBW (\%) & $146 \pm 26$ & $145 \pm 31$ \\
\hline $\mathrm{HbAlc}$ at examination $(\%)$ & $7.2 \pm 1.1$ & $7.4 \pm 1.3$ \\
\hline \multicolumn{3}{|l|}{ HbA1c Tertiles } \\
\hline$<6.8(\%)$ & $73(34.5)$ & $73(32.9)$ \\
\hline $6.8-7.6(\%)$ & $73(34.5)$ & $62(27.8)$ \\
\hline $\begin{array}{c}>7.6(\%) \\
\text { Glucose-lowering therapy }\end{array}$ & $60(28.1)$ & $80(36.2)$ \\
\hline Diet Only (\%) & $15(7.4)$ & $16(7.3)$ \\
\hline Oral Agents $(\%)^{\dagger}$ & $108(51.3)$ & $90(40.5)$ \\
\hline Sulphonylureas (\%) & $71(33.6)$ & $68(30.6)$ \\
\hline Metformin (\%) & $79(37.5)$ & $47(21.3)$ \\
\hline Thiazolinediones (\%) & $70(17.0)$ & $30(9.3)$ \\
\hline Other $(\%)$ & $6(3.1)$ & $7(3.0)$ \\
\hline Oral Agents/Insulin (\%) & $32(15.4)$ & $51(23.1)$ \\
\hline Sulphonylureas (\%) & $17(8.0)$ & $24(11.1)$ \\
\hline Metformin (\%) & $26(12.4)$ & $26(12.0)$ \\
\hline Thiazolinediones (\%) & $5(2.7)$ & $20(9.0)$ \\
\hline Other $(\%)$ & $0(0.0)$ & $1(0.8)$ \\
\hline Insulin $(\%)$ & $49(23.3)$ & $58(26.5)$ \\
\hline History of hypertension (\%) & $148(70.2)$ & $178(80.2)$ \\
\hline History of hypercholesterolemia (\%) & $172(81.4)$ & $128(85.0)$ \\
\hline Ever smoked (\%) & $77(36.6)$ & $143(64.4)$ \\
\hline Current smokers (\%) & $11(5.1)$ & $18(8.1)$ \\
\hline Former smokers $(\%)$ & $65(31.0)$ & $124(56.1)$ \\
\hline
\end{tabular}

IBW: Ideal Body Weight

The total number of subjects on oral agentsis lower than the sum of subjects in the individual oralagent classes because many subjects were on multiple medications. with $36.6 \%)$. Almost half of the cases with CAD (44.9\%) had a previous myocardial infarction.

\section{Association between 9p21 variant and CAD}

For all the investigated polymorphisms, the genotypes were in Hardy-Weinberg equilibrium in cases as well as controls. The genotype distributions for both SNPs were significantly different between cases and controls ( $\mathrm{p}=0.0002$ for $\mathrm{rs} 2383206, \mathrm{p}=0.0043$ for $\mathrm{rs} 10757278$ and rs1333049, $\mathrm{p}=0.0042$ ) (Table 2). No significant differences in genotype distributions were observed between case subjects who attended the CHU Fattouma Bourguiba Monasstir Hospital and those who did not, or between those who had a previous myocardial infarction and those who had not. Haplotype analysis indicated that the effects of rs10757278 and rs1333049 were secondary to their strong linkage disequilibrium with $\operatorname{rs} 2383206\left(D^{\prime}=1, r 2=0.77\right)$. The $G$ allele of rs2383206 was associated with CAD regardless of the rs 10757278 and rs1333049 allele that was present on the same haplotype, whereas the A allele of rs 10757278 and the allele C of rs 1333049 were protective only when they occurred together with the protective allele of rs 2383206 . The primary role of rs 2383206 in our study population was confirmed by the fact that the association with CAD disappeared for rs 10757278 $(\mathrm{p}=0.50)$ and $\mathrm{rs} 1333049(\mathrm{p}=0.47)$ whereas remained significant with rs2383206 ( $\mathrm{p}=0.012)$ when the three SNPs were analyzed together in a multivariable model. Thus, only rs 2383206 was considered in further analyses. In Table 3, we re-expressed the significant associations with $\mathrm{CAD}$ in Table 1 and those concerning the genotypes for rs 2383206 as odds ratios, both from univariable analysis and after adjustment in a multivariable model that included all the variables in the table. For the univariable analysis, ORs were 1.44 (0.95-2.23) for rs 2383206 heterozygotes and 2.38 (1.53-3.71) for allele G homozygotes, consistent with an additive mode of inheritance. Among the other variables, association with smoking was the most important ( $\mathrm{OR}=3.22,2.46-$ $4.45)$, then gender ( $\mathrm{OR}=1.74,1.27-2.37)$, antihypertensive therapy $(\mathrm{OR}=1.77,1.20-2.49)$, insulin therapy $(\mathrm{OR}=1.54,1.14-2.09)$, poor glycemic control (OR=1.44, 0.99-2.11, for the highest tertile of HbA1c at examination versus the lowest), and history of hypercholesterolemia $(\mathrm{OR}=1.31,0.84-1.93)$. All variables remained significant in a multivariable model including all other predictors, excepting insulin therapy and history of hypercholesterolemia. The ORs for rs 2383206 , both for G/G homozygotes and for heterozygotes, were similar to those obtained in univariable analysis, indicating that the effect of this SNP was not mediated by an effect on the other cardiovascular risk factors.

\section{Interaction between 9p21 variant and poor glycemic control at examination}

The possibility of an interaction with hyperglycemia, since it is the distinguishing characteristic of diabetes and excess glucose has potent proatherogenic effects, to investigate this theory, we divided study subjects according to the three rs2383206 genotypes and whether they were in the worst tertile of $\mathrm{HbAlc}$ values at examination (HbAlc $>7.6)$, the measure of glycemic control most associated with CAD in Table 1. Relative to the CAD risk for patients with neither a rs 238206 risk allele nor the worst glycemic control, the risks for those with only poor glycemic control, or only one risk allele, or only one risk allele and poor glycemic control were similarly increased, although not significantly (Table 4A) $(\mathrm{OR}=1.05,0.85-1.09$; $\mathrm{OR}=1.45,0.86-2.45$, and $\mathrm{OR}=1.72$, 0.89-3.04, respectively). By contrast, the CAD risk for subjects having two risk alleles but not poor glycemic control was increased two-fold $(\mathrm{OR}=1.98,0.98-3.11)$, whereas the risk for study subjects with the same genotype but poor glycemic control was increased fourfold $(\mathrm{OR}=4.25$, 
2.24-8.02). This effect magnification had a $\mathrm{p}$ value for interaction (i.e., deviation from additivity in the log scale) between $\mathrm{G} / \mathrm{G}$ genotype and glycemic control of 0.074 in a univariable analysis and 0.046 in a

Table 2. Genotype and allele distributions in individuals with type 2 diabetes according to coronary artery disease status.

\begin{tabular}{|c|c|c|c|}
\hline SNP & CAD-Negative $(n=212)$ & CAD-Positive $(n=222)$ & p value \\
\hline \multicolumn{4}{|l|}{ rs2383206 } \\
\hline $\mathrm{A} / \mathrm{A}$ & $43(20.3)$ & $27(12.2)$ & \\
\hline $\mathrm{A} / \mathrm{G}$ & $106(50.1)$ & $100(45.0)$ & \\
\hline $\mathrm{G} / \mathrm{G}$ & $59(27.9)$ & $91(41.3)$ & 0.0002 \\
\hline $\begin{array}{c}\text { Allele G } \\
\text { frequency }{ }^{\prime}\end{array}$ & 0.531 & 0.638 & 0.000046 \\
\hline \multicolumn{4}{|l|}{ rs10757278 } \\
\hline $\mathrm{A} / \mathrm{A}$ & $51(24.2)$ & $36(16.3)$ & \\
\hline $\mathrm{A} / \mathrm{G}$ & $107(50.5)$ & 107 (48.6) & \\
\hline $\mathrm{G} / \mathrm{G}$ & $48(23.0)$ & $73(33.1)$ & 0.0043 \\
\hline $\begin{array}{l}\text { Allele G } \\
\text { frequency }{ }^{\dagger}\end{array}$ & 0.484 & 0.567 & 0.0011 \\
\hline \multicolumn{4}{|l|}{ rs1333049 } \\
\hline $\mathrm{C} / \mathrm{C}$ & $50(24.0)$ & $35(16.0)$ & \\
\hline $\mathrm{C} / \mathrm{G}$ & $102(50.1)$ & $106(48.1)$ & \\
\hline $\mathrm{G} / \mathrm{G}$ & $40(20.0)$ & $69(30.1)$ & 0.0042 \\
\hline $\begin{array}{c}\text { Allele G } \\
\text { frequency }{ }^{\dagger}\end{array}$ & 0.480 & 0.563 & 0.0010 \\
\hline
\end{tabular}

$\%$ Based on 424 chromosomes for the CAD-Negative group and 444 chromosomes for the CAD-Positive group.

Table 3. Odds ratios for characteristics associated with coronary artery disease in patients with type 2 diabetes.

\begin{tabular}{|c|c|c|c|}
\hline Characteristic & Contrast & $\begin{array}{c}\text { Unadjusted OR (95\% } \\
\text { CI) }\end{array}$ & $\begin{array}{c}\text { Adjusted OR } \\
\text { (95\% CI) }\end{array}$ \\
\hline Gender & Male vs. female & $1.74(1.27-2.37)$ & $1.56(1.10-2.22)$ \\
\hline Smoking & Ever vs. never & $3.32(2.46-4.45)$ & $3.13(2.31-4.35)$ \\
\hline History of hypertension & Yes vs. no & $1.77(1.20-2.49)$ & $1.94(1.30-2.83)$ \\
\hline $\begin{array}{c}\text { History of } \\
\text { hypercholesterolemia }\end{array}$ & Yes vs. no & $1.31(0.84-1.93)$ & $1.29(0.81-1.89)$ \\
\hline Insulin therapy & Yes vs. no & $1.54(1.14-2.09)$ & $1.29(0.97-1.81)$ \\
\hline HbA1c & 2rdvs. 1sttertile $\dagger$ & $0.84(0.63-1.26)$ & $0.85(0.58-1.25)$ \\
\hline 3rdvs. 1sttertile $\dagger$ & $1.35(0.96-1.97)$ & $1.44(0.99-2.11)$ \\
\hline rs2383206 & A/G vs. A/A & $1.44(0.95-2.23)$ & $1.54(0.98-2.42)$ \\
\hline & G/G vs. A/A & $2.38(1.53-3.71)$ & $2.38(1.48-3.82)$ \\
\hline
\end{tabular}

$\mathrm{HbA} 1 \mathrm{c}$ tertiles boundaries are indicated in table 1 multivariable model including other cardiovascular risk factors.

\section{Interaction between $9 \mathrm{p} 21$ variant and history of poor glycemic control:}

The odds ratio was 8,11 (3.24-16.52) for subjects having both the $\mathrm{G} / \mathrm{G}$ genotype and long-term poor glycemic control as compared to 1,62 (0.79-3.34) for those with the G/G genotype but not long-term poor glycemia (Table $4 \mathrm{~B}$ ). This interaction was significant (unadjusted $p=0.0051$, adjusted $p=0.0048$ ) despite the reduced sample size and was not affected by further adjustment for mean arterial pressure and LDL (low density lipoprotein)

and HDL (High density lipoprotein) and cholesterol levels, suggesting that it was not the result of a confounding effect of worse blood pressure or lipid control among individuals with high $\mathrm{HbAlc}$ values.

\section{Interaction between 9p21 variant and poor glycemic control on mortality}

The same interaction between 9p21 high risk genotype and poor glycemic control was observed with regard to mortality in a study of $325 \mathrm{CHU}$ Fattouma Bourguiba Monastir Hospital patients who had been recruited in 2010 for genetic studies of type 2 diabetes and its complications (Table 5). Table 5 shows the cumulative 5 -year mortality in this cohort according to whether or not individuals carried the G/G genotype and whether or not they had a history of poor glycemic control (defined as the top tertile of the average HbAlc before study entry [HbAlc >8.9]). We found no significantdifferences among individuals who did not carry the G/G genotype, in either allcause or cardiovascular mortality between glycemic control groups. Contrariwise, mortality was about twice as high in individuals with poor glycemic control as compared to those in relatively good control $(\mathrm{p}=0.020$

and $\mathrm{p}=0.019$ for all-cause and cardiovascular mortality, respectively), among $\mathrm{G} / \mathrm{G}$ carriers (Table 5). The p value for interaction between poor glycemic control and G/G genotype was 0.035 for allcause and 0.043 for cardiovascular mortality.

\section{Discussion}

Several genetic variants located on chromosome 9p21.3 such as SNP rs2383206, rs1333049 and rs10757278 are important risk factors for coronary artery disease in type 2 diabetic patients. In our study

Table 4. Synergism between poor glycemic control and SNP rs 2383206 on the odds of CAD in type 2 diabetes.

\begin{tabular}{|c|c|c|c|c|}
\hline & \multicolumn{2}{|c|}{ A. HbA1c at examination } & \multicolumn{2}{|c|}{ B. HbA1c before examination } \\
\hline & $1^{\text {st }}$ or $2^{\text {nd }}$ tertile $(\leq 7.6 \%)$ & $3^{\text {rd }}$ Tertile $(>7.6 \%)$ & $1^{\text {st }}$ or $2^{\text {nd }}$ tertile $(\leq 7.9 \%)$ & $3^{\text {rd }}$ Tertile $(>7.9 \%)$ \\
\hline Rs2383206 & OR (CI 95\%) & OR (CI 95\%) & OR (CI 95\%) & OR (CI 95\%) \\
\hline $\begin{array}{l}\mathbf{A} / \mathbf{A} \\
\mathbf{A} / \mathbf{G} \\
\mathbf{G} / \mathbf{G}\end{array}$ & $\begin{array}{l}1,05(0.85-1.09) \\
1,45(0.86-2.45) \\
1,72(0.89-3.04)\end{array}$ & $\begin{array}{l}1,50(0,51-2,53) \\
1,98(0.98-3.11) \\
4,25(2.24-8.02)\end{array}$ & $\begin{array}{l}1,09(0.86-1.12) \\
1,52(0.76-3.25) \\
1,62(0.79-3.34)\end{array}$ & $\begin{array}{c}2,50(0,78-5,13) \\
2,98(1.98-4.10) \\
8,11(3.24-16.52)\end{array}$ \\
\hline
\end{tabular}

\begin{tabular}{|c|c|c|c|c|c|c|c|c|}
\hline \multirow[b]{3}{*}{ Rs2383206 } & \multicolumn{4}{|c|}{ A. HbA1c at examination } & \multicolumn{4}{|c|}{ B. Average HbA1c before examination } \\
\hline & \multicolumn{2}{|c|}{$1^{\text {st }}+2^{\text {nd }}$ tertile $(\leq 7.6 \%)$} & \multicolumn{2}{|c|}{$3^{\text {rd }}$ Tertile $(>7.6 \%)$} & \multicolumn{2}{|c|}{$1^{\text {st }}+2^{\text {nd }}$ tertile $(\leq 7.9 \%)$} & \multicolumn{2}{|c|}{$3^{\text {rd }}$ Tertile $(>7.9 \%)$} \\
\hline & CAD- & CAD+ & CAD- & CAD+ & CAD- & CAD+ & CAD- & CAD+ \\
\hline $\begin{array}{l}\text { A/A } \\
\text { A/G } \\
\text { G/G }\end{array}$ & $\begin{array}{c}61(20,1) \\
136(45,5) \\
89(30,1)\end{array}$ & $\begin{array}{l}27(12,5) \\
89(46,3) \\
79(39,6)\end{array}$ & $\begin{array}{c}22(18,6) \\
67(53) \\
27(22,8)\end{array}$ & $\begin{array}{l}12(10,3) \\
52(43,1) \\
54(44,1)\end{array}$ & $\begin{array}{c}53(20,3) \\
121(45,9) \\
78(33,1)\end{array}$ & $\begin{array}{l}13(14,9) \\
40(49,9) \\
26(33,8)\end{array}$ & $\begin{array}{l}15(16,6) \\
56(57,4) \\
22(23,7)\end{array}$ & $\begin{array}{c}6(8,9) \\
25(33,6) \\
39(53,9)\end{array}$ \\
\hline
\end{tabular}

A. Adjust edoddsratios of CAD according to HbA1 cvalueat examination (toptertilevs.lower two tertiles) and genotypes at rs 2383206 . Individuals with no risk alleles and HbA1c in the lower two tertiles serve as reference. B. Adjusted odds ratios of CAD according to the time-weighted average HbA1c during the years before study entry (top tertile vs. lower two tertiles) and genotypes at rs 2383206 . The top tertile boundaries were 7.6 for $\mathrm{HbAlc}$ at examination and 7.9 for the average HbAlc in the years before examination. The counts of individuals in each stratum are reported below eachchart. 
population of diabetic subjects, this effect is stronger than that reported in the general population, which seems to be owing to a positive interaction between the genetic variant(s) and hyperglycemia. This association in the general population, is not mediated by an effect of these genetic variants on other cardiovascular risk factors, since it is not attenuated by adjustment for these variables $[12,19]$. This synergism between 9p21.3 locus and hyperglycemia on the risk of CAD translates into a similar interaction with regards to cardiovascular mortality among individuals with type 2 diabetes.

The contradiction between the potent proatherogenic effects of glucose observed in vitro and the evidence from large clinical trials of limited benefit of good glycemic control on cardiovascular outcomes in diabetic subjects may be explained by the interaction between $9 \mathrm{p} 21.3$ allele and glycemic control [20-22]. Poor glycemic control has an important effect on cardiovascular risk in homozygous GG patients at rs 2383206 , about $30 \%$ of type 2 diabetic patients. The other $70 \%$ are not as sensitive to the atherogenic effects of hyperglycemia. In contrary with our results, Broadbent et al. found that the strength of the association between 9p21 variant and CAD was similar among diabetic and nondiabetic subjects [23].

Our findings are absolutely in agreement with Doria and al., who found that the CAD risk associated with the 9p21 variant was increased

Table 5. Baseline characteristics of the CHU Fattouma Bourguiba Monastir Hospital cohort investigated in the prospective study.

\begin{tabular}{|c|c|}
\hline N & 325 \\
\hline Men (\%) & $174(53.7)$ \\
\hline Age at examination (yrs) & $57 \pm 9$ \\
\hline Age at Diabetes Dx (yrs) & $44 \pm 8$ \\
\hline Diabetes Duration (yrs) & $14 \pm 7$ \\
\hline Percent IBW (\%) & $135 \pm 32$ \\
\hline HbA1c (\%) $\dagger$ & $8.4 \pm 1.5$ \\
\hline HbA1c Tertiles & $107(33.1)$ \\
\hline$<7.8(\%)$ & $111(34.2)$ \\
\hline $7.8-8.9(\%)$ & $105(32.4)$ \\
\hline$>8.9(\%)$ & \\
\hline
\end{tabular}

Glucose-lowering therapy

\begin{tabular}{|c|c|}
\hline Diet Only (\%) & $28(8.6)$ \\
\hline Oral Agents (\%) & $93(28.6)$ \\
\hline Oral Agents/Insulin (\%) & $14(4.4)$ \\
\hline Insulin (\%) & $190(58.6)$ \\
\hline
\end{tabular}

IBW: Ideal Body Weight

$\uparrow$ Average $\mathrm{HbAlc}$ value before recruitment

ๆSubjects treated with both oral agents and insulin. in the presence of poor glycemic control in type 2 diabetes [18]. Their study, like ours, has two unique strengths: first, the contrast achieved by comparing angiographically-confirmed CAD cases with controls for whom CAD was ruled out by an exercise stress test, and second, the accurate assessment of long-term glycemic control through multiple HbAlc measurements spanning many years before study entry, in contrast to the crosssectional measurements available to most studies of CAD in type 2 diabetes.

\section{Conclusion}

The main conclusion of the current study was that $9 \mathrm{p} 21.3$ locus and poor glycemic control interact in determining the risk of CAD in type 2 diabetes. Our finding may help us to understand implications of atherogenesis in diabetes and for the design of more effective prevention strategies.

\section{References}

1. Stamler J, Vaccaro O, Neaton JD, Wentworth D (1993) Diabetes, other risk factors, and 12-yr cardiovascular mortality for men screened in the Multiple Risk Factor Intervention Trial. Diabetes Care 16: 434-444. [Crossref]

2. Beckman JA, Creager MA, Libby P (2002) Diabetes and atherosclerosis: epidemiology, pathophysiology, and management. JAMA 287: 2570-2581. [Crossref]

3. Abbott RD, Brand FN, Kannel WB (1990) Epidemiology of some peripheral arterial findings in diabetic men and women: experiences from the Framingham Study. Am J Med 88: 376-381. [Crossref]

4. Folsom AR, Rasmussen ML, Chambless LE, Howard G, Cooper LS, et al. (1999) Prospective associations of fasting insulin, body fat distribution, and diabetes with risk of ischemic stroke. The Atherosclerosis Risk in Communities (ARIC) Study Investigators. Diabetes Care 22: 1077-1083. [Crossref]

5. Warram JH, Kopczynski J, Janka HU, Krolewski AS (1997) Epidemiology of noninsulin-dependent diabetes mellitus and its macrovascular complications. A basis for the development of cost-effective programs. Endocrinol Metab Clin North Am 26: 165 188. [Crossref]

6. Shea S, Ottman R, Gabrieli C, Stein Z, Nichols A (1984) Family history as an independent risk factor for coronary artery disease. J Am Coll Cardiol 4: 793-801. [Crossref]

7. Marenberg ME, Risch N, Berkman LF, Floderus B, de Faire U (1994) Genetic susceptibility to death from coronary heart disease in a study of twins. $N$ Engl $J$ Med 330: 1041-1046. [Crossref]

8. Wagenknecht LE, Bowden DW, Carr JJ, Langefeld CD, Freedman BI, et al (2001) Familial aggregation of coronary artery calcium in families with type 2 diabetes. Diabetes 50: 861-866. [Crossref]

9. Lange LA, Bowden DW, Langefeld CD, Wagenknecht LE, Carr JJ, et al. (2002) Heritability of carotid artery intima-medial thickness in type 2 diabetes. Stroke 33: 1876-1881. [Crossref]

10. Abid K, Mili D, Trimeche T, Msolli M A, Trabelsi I, et al. (2015) Association of the Locus 9p21.3 with Coronary Artery Disease in Type 2 Diabetic Patients. Journal of

Table 6. Cumulative 5-year mortality in 325 CHU FattoumaBourguibaMonastir Hospital patients with type 2 diabetes according to degree of glycemic control before study entry and 9p 21.3 genotype.

\begin{tabular}{|c|c|c|c|c|c|c|c|c|c|c|}
\hline \multirow{2}{*}{\multicolumn{2}{|c|}{ Group }} & \multirow[b]{3}{*}{$\mathbf{N}$} & \multicolumn{8}{|c|}{ Cumulative 5-year mortality } \\
\hline & & & \multicolumn{4}{|c|}{ All-Cause } & \multicolumn{4}{|c|}{ CVD } \\
\hline rs2383206 & HbA1c tertile ${ }^{\prime}$ & & $\%(n) \S$ & $95 \% \mathrm{CI}$ & p & pq & $\%(n) \S$ & $95 \%$ CI & p*: & pब \\
\hline $\mathrm{A} / \mathrm{A}+\mathrm{A} / \mathrm{G}$ & $1^{\text {st }}+2^{\text {nd }}$ & 145 & $31.5(45)$ & $25.0-38.0$ & & & $19.6(28)$ & $13.8-25.6$ & & \\
\hline $\mathrm{A} / \mathrm{A}+\mathrm{A} / \mathrm{G}$ & $3^{\text {rd }}$ & 72 & $30.1(9)$ & $20.6-39.1$ & 0.75 & & $20.0(14)$ & $11.5-28.3$ & 0.92 & \\
\hline $\mathrm{G} / \mathrm{G}$ & $1^{\mathrm{st}}+2^{\text {nd }}$ & 74 & $23.2(17)$ & $14.8-31.6$ & & & $15.2(11)$ & $8.1-22.7$ & & \\
\hline $\mathrm{G} / \mathrm{G}$ & $3^{\text {rd }}$ & 34 & $43.7(15)$ & $28.6-58.8$ & 0.02 & 0.035 & $35.5(12)$ & $20.4-51.6$ & 0.019 & 0.043 \\
\hline
\end{tabular}

†rd tertile boundary $=8.9 \%$.

$\S$ The numbers in parentheses are the numbers of deaths observed in each group. Percent mortalities and their confidence intervals were obtained by lifetable methods. Hence the percents do not exactly correspond to the number of deaths divided by the sample size.

$\neq 3^{\text {rd }}$ vs. $1^{\text {st }}+2^{\text {nd }}$ tertiles of HbA1c.

ๆInteraction between HbA1c tertile group and rs2383206 genotype. 
Cardiovascular Disease 3: 381-386.

11. Abid K, Mili D, Kenani A (2015) Polymorphism on Chromosome 9p21.3 Is Associated with Severity and Early-Onset CAD in Type 2 Diabetic Tunisian Population. Dis Markers 2015: 792679. [Crossref]

12. McPherson R, Pertsemlidis A, Kavaslar N, Stewart A, Roberts R, et al. (2007) A common allele on chromosome 9 associated with coronary heart disease. Science 316 : 1488-1491. [Crossref]

13. Welcome Trust Case Control Consortium (2007) Genome-wide association study of 14,000 cases of seven common diseases and 3,000 shared controls. Nature 447: 661678. [Crossref]

14. (1997) Report of the Expert Committee on the Diagnosis and Classification of Diabetes Mellitus. Diabetes Care 20: 1183-1197. [Crossref]

15. Gibbons RJ, Balady GJ, Beasley JW, Bricker JT, Duvernoy WF, et al. (2002) ACC AHA 2002 guideline update for exercise testing: summary article. A report of the American College of Cardiology/American Heart Association Task Force on Practice Guidelines (Committee to Update the 1997 Exercise Testing Guidelines). J Am Coll Cardiol 40: 1531-1540. [Crossref]

16. Freire MB, Ji L, Onuma T, Orban T, Warram JH, et al. (1998) Gender-specific association of M235T polymorphism in angiotensinogen gene and diabetic nephropathy in NIDDM. Hypertension 31: 896-899. [Crossref]
17. Scheffold T, Kullmann S, Huge A, Binner P, Ochs HR, et al. (2011) Six sequence variants on chromosome $9 \mathrm{p} 21.3$ are associated with a positive family history of myocardial infarction: a multicenter registry. BMC Cardiovascular Disorders 11: 9.

18. Doria A, Wojcik J, Xu R, Gervino EV, Hauser TH, et al. (2008) Interaction between poor glycemic control and 9p21 locus on risk of coronary artery disease in type 2 diabetes. JAMA 300: 2389-2397. [Crossref]

19. Helgadottir A, Thorleifsson G, Manolescu A, Gretarsdottir S, Blondal T, et al. (2007) A common variant on chromosome 9p21 affects the risk of myocardial infarction. Science 316: 1491-1493. [Crossref]

20. Libby P, Plutzky J (2002) Diabetic macrovascular disease: the glucose paradox? Circulation 106: 2760-2763. [Crossref]

21. (1998) Intensive blood-glucose control with sulphonylureas or insulin compared with conventional treatment and risk of complications in patients with type 2 diabetes (UKPDS 33). UK Prospective Diabetes Study (UKPDS) Group. Lancet 352: 837-853. [Crossref]

22. Haffner SM (1999) Epidemiological studies on the effects of hyperglycemia and improvement of glycemic control on macrovascular events in type 2 diabetes. Diabetes Care 22: C54-6. [Crossref]

23. Broadbent HM, Peden JF, Lorkowski S, Goel A, Ongen H, et al. (2008) Susceptibility to coronary artery disease and diabetes is encoded by distinct, tightly linked SNPs in the ANRIL locus on chromosome 9p. Hum Mol Genet 17: 806-814. [Crossref]

Copyright: (C2016 Kaouthar A. This is an open-access article distributed under the terms of the Creative Commons Attribution License, which permits unrestricted use, distribution, and reproduction in any medium, provided the original author and source are credited. 